\title{
Terminal Deoxynucleotidyl Transferase in type B Acute Lymphoblastic Leukemia
}

\begin{abstract}
Terminal deoxynucleotidyl transferase (TdT or DNTT) is a nuclear enzyme whose expression is restricted to normal tissue (thymus and bone marrow) and to lymphoid precursors of the B and T cell. TdT catalyzes the addition of deoxynucleotides independently of the template in the 3'-terminal hydroxyl end of the oligonucleotide primers. In addition, it plays a crucial role in the insertion of $\mathrm{N}$ regions during the rearrangement of immunoglobulin genes and receptor $T$ and $B$ cells (TCR and BCR) at the DJ binding sites and variable (V) diversity (D) binding (J). This mechanism of the diversity of the binding is essential for the development of a repertoire of immunoglobulin's and B and T cell receptors. TdT is expressed in malignant lymphoblastic tumors of precursors, including precursors of $B$ and T cells. In this review, we describe the biological importance of TdT in acute lymphoblastic leukemia of type B cells.
\end{abstract}

Keywords: Terminal deoxynucleotidyl transferase rearrangement of immunoglobulin genes and acute lymphoblastic leukemia of type B cells.

\section{Functions of TdT}

The ability of the immune system to respond to the wide range of potential pathogens that infect us during the development of life depends on the diverse repertoire of antigenic receptors expressed by $\mathrm{B}$ and $\mathrm{T}$ lymphocytes $[1,2]$. The great diversity of antigenic receptors is largely generated part by the recombination process $\mathrm{V} \mathrm{D}$ J, in which DNA elements are randomly linked to form the variable domains of the antigenic receptor genes [3]. Generation of the functional heavy chain $(\mathrm{H})$ and light $(\mathrm{L})$ genes from immunoglobulin's through V D $\mathrm{J}$ recombination occurs in a gradual process during the development of $B$ cells in the primary lymphoid organs such bone marrow and the spleen. Among the key enzyme in this process is the terminal deoxynucleotidyl transferase enzyme (TdT or DNTT) [4].

The gene from TdT is located on chromosome 10q23-q25, This gene is a member of the X-type DNA polymerase family that codes for a $58-\mathrm{kDa}$ DNA polymerase independent of the template that catalyzes the addition of deoxynucleotides to the 3'-hydroxyl terminus of the oligonucleotide primers $[5,6]$.

$\mathrm{TdT}$ is responsible for the addition of random nucleotides in the junction ( $\mathrm{N}$ region) of the heavy chain of rearranged Ig, during recombination of $\mathrm{V} \mathrm{D} \mathrm{J}$ in the maturation of $\mathrm{B}$ and $\mathrm{T}$ cells, playing an important role in the development and variations of antigenic receptors in the immune system. Transcriptionally $\mathrm{TdT}$ is regulated by transcription factors such as AP-1, as well as through recombinant gene expression activators (RAG). TdT activity can also be regulated at the post-transcriptional level by phosphorylation. Another group of proteins that also regulate the TdT activity is known as $\mathrm{TdT}$ interaction factors (TdiF1) [7-11].

\section{Journal of}

Human Anatomy \& Physiology

\author{
Luis Antonio Martínez-Jiménez ${ }^{1}$, Jorge Organista- \\ Nava1, Berenice Illades-Aguiar ${ }^{1}$, Leyva-Vazquez \\ $\mathbf{M}^{1^{*}}$, and Yazmín Gómez-Gómez ${ }^{1^{*}}$ \\ Laboratorio de Biomedicine Molecular, Facultad de Ciencias \\ Químico-Biológicas, Universidad Autónoma de Guerrero, \\ Chilpancingo, Guerrero, México
}

\section{*Address for Correspondence}

Yazmín Gómez-Gómez, Laboratorio de Biomedicine Molecular, Facultad de Ciencias Químico-Biológicas, Universidad Autónoma de Guerrero, Chilpancingo, Guerrero, México. E-mail: yazmigomezgomez@gmail.com Marco Antonio Leyva-Vázquez, Laboratorio de Biomedicine Molecular, Facultad de Ciencias Químico-Biológicas, Universidad Autónoma de Guerrero, Chilpancingo, Guerrero, México.

E-mail: leyvamarco13@gmail.com

Submission: 01 January, 2019

Accepted: 01 February, 2019

Published: 20 February, 2019

Copyright: ๑ 2019 Martínez-Jiménez LA, et al. This is an open access article distributed under the Creative Commons Attribution License, which permits unrestricted use, distribution, and reproduction in any medium, provided the original work is properly cited.

Since that the cloning trials from TdT were initiated, there was an increase in knowledge about properties and functions under normal and pathological conditions of TdT, In humans, the expression of $\mathrm{TdT}$ is restricted in lymphoid precursors of lineage $\mathrm{T}$ and $\mathrm{B}$, and in hematological cancers. TdT isoforms are slightly more complicated as each have three alternative splice variants designated as TdTS (short), TdTL1 (long) and TdTL2 (long) [12,13]. There is evidence of possible human isoforms of TdT (hTdT) derived from the genomic sequences of hTdT, which led to the identification of the short isoform (hTdTS), as well as the mature long transcripts that contain exon XII (hTdTL1) and another that includes the exon VII (hTdTL2) in lymphoid cells [14].

Normal B and T lymphocytes express exclusively hTdTS and hTdTL2, whereas expression of hTdTL1 appears to be restricted to transformed lymphoid cell lines [15].

The newly discovered hTdT isoforms should be considered in the future examination of human leukemias [16].

The structure-function analysis of the murine TdT protein was also performed to determine the functions of the structural motifs that have been implicated in protein-protein and DNA-protein interactions. In this analysis was demonstrated that the N-terminal portion of TdT, including the C-terminal BRCA-1 domain (BRCT), is not required for TdT activity, although the BRCT domain contributes to the activity of adding $\mathrm{N}$-nucleotide [17].

The second helix-hairpin-helix domain of TdT, but not the first, is required for this activity. The deletion analysis also suggested that the complete C-terminal region of $\mathrm{TdT}$ is necessary for the addition of 


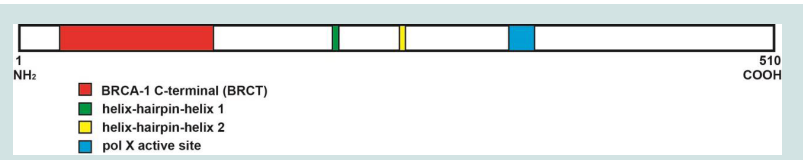

Figure 1: Structure of TdT-FL. The domains of TdT are depicted as rectangles and labeled as follows: BRCA-1 C-terminal domain (BRCT), helixhairpin-helix ( $\mathrm{HhH} 1$ and $\mathrm{HhH} 2)$, and pol $\mathrm{X}$ active site.

$\mathrm{N}$-nucleotide in vivo Homology among members of the pol X family is not limited to their catalytic center (amino acid position 332 to 349). Additional domains shared by several of these polymerases include BRCA-1 C-terminal (BRCT) domains as well as helix-hairpin-helix (HhH) domains, The BRCT domain is a phosphopeptide binding motif that mediates protein-protein interactions and is commonly found in proteins involved in DNA recombination and repair, such as BRCA-1, XRCC4, and DNA ligase IV (amino acid position 26 to 130) [18-20]. (Fig, 1).

HhH domains are non sequence-specific DNA binding motifs that contact DNA by interactions of peptide backbone nitrogen atoms with phosphate groups of the DNA (HhH1 amino acid position 213 to 218) ( $\mathrm{HhH} 2$ amino acid position 257 to 261), It has been shown that TdT plays a very important role in the development of B lymphocytes in fetal development since it has been observed that the precursors of B cells from lymph nodes are positive for TdT [21, 22].

Biases in the recombination process and/or cellular selection through Ig receptors are thought to account for the nonrandom nature of the Ig repertoire; however, the details of these selection mechanisms and the relative impact of each type of selection mechanism on the Ig repertoire have not been determined. The Ig H chain repertoire displays two interesting nonrandom characteristics that have been particularly well studied:

\section{Unequal usage of $D_{H}$ reading frames $(R F)$, and}

2. Over usage of the $\mathrm{V}_{\mathrm{H}} 81 \mathrm{x}$ gene segment [23-25].

However, during neonatal life the immunoglobulin diversity is limited and the absence of TdT expression with the consequent lack of addition not contemplated during the neonatal period, and together with the predominant use of a single $\mathrm{D}_{\mathrm{H}}$ reading frame, leads to serious limitations of diversity in the CDR3 region of Ig Heavy chains (H). The repertoire of the neonatal Ig $\mathrm{H}$ chain is also characterized by the restricted use of $\mathrm{V}_{\mathrm{H}}$, with predominant expression of certain $\mathrm{V}_{\mathrm{H}}$ segments, such as $\mathrm{V}_{\mathrm{H}} 81 \mathrm{x}$, which are rarely evident during adult life. When the expression of TdT is induced in the neonatal repertoire of $\mathrm{V}_{\mathrm{H}} 81 \mathrm{xDJ}_{\mathrm{H}}$, the synthesis of TdT cancels the bias in the reading frame $\mathrm{D}_{\mathrm{H}}$ during the fetal/neonatal period through an independent mechanism of the Ig receptor. These findings suggest that the bias of the $\mathrm{D}_{\mathrm{H}}$ reading frame during neonatal life is determined to a large extent by homology-directed binding [26].

Also found, was that the synthesis of TdT alters the selection of productively rearranged $\mathrm{V}_{\mathrm{H}} 81 \mathrm{xDJ}_{\mathrm{H}}$ alleles in the neonatal spleen through an Ig-dependent mechanism. These results demonstrate that TdT can indirectly influence the Ig repertoire by influencing the selection processes dependent on the receptor and the independent receptor [27]. It has been reported that TdT play a very important role in the ontogeny of B lymphocytes in adults, since in one study a relationship between the expression of TdT with specific markers of lineage B (CD19) was demonstrated, but the expression of CD19 did not, it is a marker of early ontogeny of B lymphocytes, therefore it can be used to CD79a, which is highly specific for B cells and which can also be expressed very early in ontogenesis, In the same way, it was demonstrated that TdT has the same function in the development of $\mathrm{B}$ lymphocytes in a murine model because it increases the insertion in the N-region in pre-B cells, It is also known that TdT is involved in the ontogeny of T lymphocytes [16, 28-30].

\section{Tdt in Leukemia}

Leukemia is a type of blood cancer, which starts in bloodforming tissue, such as the bone marrow, and causes large numbers of immature blood cells to be produced and enter the bloodstream. Leukemia is subdivided into different subtypes according to cellular maturity (acute or chronic) and cell type (lymphocytic or myeloid). Acute lymphoblastic leukemia (ALL) is a cancer of lymphocytes, a type of white blood cell that is part of the body's immune system. ALL is the most common cancer in children under 18 , the great majority of ALL is of type B lineage (75-80\%). In studies on TdT in subjects with acute leukemia, an increase in its expression was observed, In 1978 , it is described for the first time that there is a higher percentage of TdT expression in leukocytes of B-type ALL than in type T, and in experimentally demonstrating the biological role not only in B cell proliferation [31-34].

In a study in which it was evaluated, the activity of TdT in samples of bone marrow and peripheral blood of patients with various types of leukemia such as acute myeloblastic leukaemia and chronic granulocytic leukaemia, it was reported that there is an increase in the activity of TdT in those patients with ALL. In another study, they conclude that the assay of TdT in the peripheral blood or bone marrow of patients with acute leukemia is of value in differentiating lymphoid (including non-T non-B) from myeloid leukemia [35, 36].

Since then TdT has been used as a diagnostic marker of ALL implementing microscopy methods as main tools; immunofluorescence and immunohistochemistry [37]. But because there are reports of positive TdT cells in acute myeloid leukemias, their diagnostic value has been questioned [38]. An alternative that has been employed is the use of flow cytometry as a method that allows quantitative analysis, since it recognizes differences between ALL and AML. In a study performed on subjects with B-ALL, high levels of TdT was observed, while AML had low levels [39]. For this reason, TdT can be an effective biomarker for classifying leukemias of lymphoid origin, in the same way, it is valuable to define the stages of maturation of leukemias [40].

It has recently been shown that the expression of $\mathrm{TdT}$ increases in the presence of different cytosines (IL-2, IL-7, and IL-15) and that inhibiting $\mathrm{TdT}$ reduces the expansion of $\mathrm{B}$ and $\mathrm{T}$ cells and therefore both decreases apoptosis and proliferation [41]. On the other hand, a high number of TdT-positive cells has been reported in inflamed pediatric kidneys in children with lymphoblastic leukemia [42]. It has also been reported that in pediatric patients with ALL who overexpress miR-125b, miR-100, and miR-99a are resistant to treatment with vincristine and that it reduces the expression of 11 
Citation: Martínez-Jiménez LA, Organista-Nava J, Illades-Aguiar B, Leyva-Vazquez M, Gómez-Gómez Y, Terminal Deoxynucleotidyl Transferase in type B Acute Lymphoblastic Leukemia. J Hum Anat Physiol 2019;3(1): 4.

genes, including TdT [43].

\section{Conclusion}

In spite of the great scientific advance that has extended the knowledge on the process of leukemogenesis, little is known about the molecular events that participate in the development of ALL. TdT is an enzyme that is involved in the ontogeny of B lymphocytes in a normal way. There are also articles that report the altered expression of TdT in type B ALL. TdT expression is currently evaluated through immunohistochemistry, immunofluorescence and flow cytometry. Therefore, an alternative treatment be to inhibit the expression of TdT plus the combination with routine treatments for type B ALL.

\section{References}

1. Burger JA, Wiestner A (2018) Targeting B cell receptor signalling in cancer: preclinical and clinical advances. Nat Rev Cancer 18: 148-167.

2. Huse M (2009) The T-cell-receptor signaling network. J Cell Sci 122: 12691273.

3. Alt FW, Yancopoulos GD, Blackwell TK, Wood C, Thomas E, et al. (1984) Ordered rearrangement of immunoglobulin heavy chain variable region segments. EMBO J 3: 1209-1219.

4. Market E, Papavasiliou FN (2003) V(D)J recombination and the evolution of the adaptive immune system. PLoS Biol 1: E16.

5. Isobe M, Huebner K, Erikson J, Peterson R, Bollum F, etal. (1985) Chromosome localization of the gene for human terminal deoxynucleotidyltransferase to region 10q23-q25. Proc Natl Acad Sci 82: pp. 5836-5840.

6. Coleman MS, Hutton JJ, De Simone P, Bollun FJ (1974) Terminal Deoxyribonucleotidyl Transferase in Human Leukemia. PNAS 71: 4404-4408.

7. Bertocci B, De Smet A, Weill JC, Reynaud CA (2006) Nonoverlapping functions of DNA polymerases mu, lambda, and terminal deoxynucleotidyltransferase during immunoglobulin $\mathrm{V}(\mathrm{D}) \mathrm{J}$ recombination in vivo. Immunity 25: 31-41.

8. Peralta ZO, Targa RF, Marina MV (2004) Terminal deoxynucleotidy transferase is down-regulated by AP-1-like regulatory elements in human lymphoid cells. Immunology 111: 195-203.

9. McBlane JF, van Gent DC, Ramsden DA, Romeo C, Cuomo CA, et al. (1995) Cleavage at a $\mathrm{V}(\mathrm{D}) \mathrm{J}$ recombination signal requires only RAG1 and RAG2 proteins and occurs in two steps. Cell 83: 387-395.

10. Elias L, Longmire J, Wood A, Ratliff R (1982) Phosphorylation of termina deoxynucleotidyl transferase in leukemic cells. Biochem Biophy Res Commun 106: 458-465

11. Fujita K, Shimazaki N, Ohta Y, Kubota T, Ibe S, et al. (2003) Termina deoxynucleotidyltransferase forms a ternary complex with a novel chromatin remodeling protein with $82 \mathrm{kDa}$ and core histone. Genes Cells 8: 559-571.

12. Peterson RC, Cheung LC, Mattaliano RJ, Chang LM, Bollum FJ (1984) Molecular cloning of human terminal deoxynucleotidyltransferase. Proc Natl Acad Sci 81: 4363-4367.

13. Thai TH, Purugganan MM, Roth DB, Kearney JF (2002) Distinct and opposite diversifying activities of terminal transferase splice variants. Nat Immunol 3 : 457-462.

14. Klein U, Küppers R, Rajewsky K (1999) Phenotypic and Molecular Characterization of Human Peripheral Blood B-cell Subsets with Special Reference to N-Region Addition and $\mathrm{JK}_{\mathrm{K}}$-Usage in $\mathrm{VK}_{\mathrm{K}} \mathrm{J}$-Joints and $\mathrm{K} / \mathrm{\lambda}$-Ratios ixn Naive Versus Memory B-cell Subsets to Identify Traces of Receptor Editing Processes. Curr Top microbiol immunol 246: 141-147.

15. Klein R, Jaenichen R, Zachau H (1993) Expressed human immunoglobulin $x$ genes and their hypermutation. Eur J Immunol 23: 3248-3271.

16. Thai T, Kearney J (2004) Distinct and Opposite Activities of Human Termina Deoxynucleotidyltransferase Splice Variants. J Immunol 173: 4009-4019.
17. Manke IA, Lowery DM, Nguyen A, Yaffe MB (2003) BRCT Repeats As Phosphopeptide-Binding Modules Involved in Protein Targeting. Science 302: 636-639.

18. 18. Repasky JA, Corbett E, Boboila C, Schatz DG (2004) Mutational Analysis of Terminal Deoxynucleotidyltransferase- Mediated N-Nucleotide Addition in V(D)J Recombination. J Immunol 172: 5478-5488.

19. Yu X, Silva CC, He M, Mer G, Chen J (2003) The BRCT Domain is a PhosphoProtein Binding Domain. Science 302: 639-642.

20. Zhang X, Moréra S, Bates PA, Whitehead PC, Coffer Al, et al. (1998) Structure of an XRCC1 BRCT domain: a new protein-protein interaction module. EMBO J 17: 6404-6411.

21. Doherty AJ, Serpell LC, Ponting CP (1996) The helix-hairpin-helix DNAbinding motif: a structural basis for non-sequence-specific recognition of DNA. Nucleic Acids Res 24: 2488-2497.

22. Cattoretti G, Parravicini C, Bonati A, Buscaglia M, Zuliani G, et al. (1989) Terminal deoxynucleotidyl transferase positive $B$ cell precursors in fetal lymph nodes and extrahemopoietic tissues. Eur J Immunol 19: 493-500.

23. Perlmutter RM, Kearney JF, Chang SP, Hood LE (1985) Developmentally controlled expression of immunoglobulin VH genes. Science 227: 1597-1601.

24. Kepler TB, Borrero M, Rugerio B, McCray SK, Clarke SH (1996) Interdependence of N Nucleotide Addition and Recombination Site Choice in V(D)J Rearrangement. J Immunol 157: 4451-4457.

25. Yancopoulos G, Desiderio S, Paskind M, Kearney J, Baltimore D, et al. (1984) Preferential utilization of the most $J_{H}$-proximal $V_{H}$ gene segments in pre-B-cell lines. Nature 311: 727-733.

26. Feeney $A(1990)$ Lack of $\mathrm{N}$ regions in fetal and neonatal mouse immunoglobulin V-D-J junctional sequences. J Exp Med 172: 1377-1390.

27. Marshall AJ, Doyen N, Bentolila LA, Paige CJ, Wu GE (1998) Terminal Deoxynucleotidyl Transferase Expression During Neonatal Life Alters DH Reading Frame Usage and Ig-Receptor-Dependent Selection of V Regions. J Immunology 161: 6657-6663.

28. Dworzak MN, Fritsch G, Fröschl G, Printz D, Gadner H (1998) Four-Color Flow Cytometric Investigation of Terminal Deoxynucleotidyl TransferasePositive Lymphoid Precursors in Pediatric Bone Marrow: CD79a Expression Precedes CD19 in Early B-Cell Ontogeny. Blood 92: 3203-3209.

29. Greenberg JM, Kersey JH, (1987) Terminal deoxynucleotidyl transferase expression can precede $\mathrm{T}$ cell receptor beta chain and gamma chain rearrangement in T cell acute lymphoblastic leukemia. Blood 69: 356-360.

30. Okamura S, Cran F, Messner HA, Mak TW (1978) Purification of Terminal Deoxynucleotidyltransferase by Oligonucleotide Affinity Chromatography. J Biol Chem 253: 3765-3667.

31. Terwilliger T, Abdul-Hay M (2017) Acute lymphoblastic leukemia: a comprehensive review and 2017 update. Blood Cancer 7: e577.

32. Bhattacharyya JR (1975) Terminal deoxyribonucleotidyl transferase in human leukemia. Biochem Biophys Res Commun 62: 367-375.

33. Marcus SL, Smith SW, Jarowski Cl, Modak JM (1976) Terminal deoxyribonucledtidyl transferase activity in acute undifferentiated leukemia. Bioche Biophys Res Commun 70: 37-44.

34. Shaw MT, Dwyer JM, Allaudeen HS, Weitzman HA (1978) Terminal Deoxyribonucleotidyl Transferase Activity in B-Cell Acute Lymphocytic Leukemia. Blood 51: 181-187.

35. YasminehWG, SmithBM,Bloomfleld CD(1980)DNAnucleotidylexotransferase of normal persons and leukemic patients. Clin Chem 26: 891-895.

36. Hoffbrand AV, Ganeshagurua K, Janossy G, Greaves MF, Catovsky D, et al. (1977) Terminal deoxynucleotidyl-transferase levels and membrane phenotypes in diagnosis of acute leukæmia. Lancet 310: 520-523.

37. Drexler HG, Menon M, Minowada J (1986) Incidence of TdT Positivity in Cases of Leukemia and Lymphoma. Acta Haematol 75: 12-17. 
Citation: Martínez-Jiménez LA, Organista-Nava J, Illades-Aguiar B, Leyva-Vazquez M, Gómez-Gómez Y, Terminal Deoxynucleotidyl Transferase in type B Acute Lymphoblastic Leukemia. J Hum Anat Physiol 2019;3(1): 4.

38. Almasri NM, Iturraspe JA, Benson NA, Chen MG, Braylan RC (1991) Flow Cytometric Analysis of Terminal Deoxynucleotidyl Transferase. Am J Clin Pathol 95: 376-380.

39. Farahat N, Lens D, Morilla R, Matutes E, Catovsky D, et al (1995) Differentia TdT expression in acute leukemia by flow cytometry: A quantitative study. Leukemia 9: 583-587.

40. Onciu M, Lorsbach RB, Charlene HE, Behm FG (2002) Terminal Deoxynucleotidyl Transferase-Positive Lymphoid Cells in Reactive Lymph
Nodes From Children With Malignant Tumors. Am J Clini Pathol 118: 248254.

41. Gholami S, Mohammadi SM, Movasaghpour AA, Abedelahi A, Alihemmati A, et al. (2017) Terminal Deoxynucleotidyl Transferase (TdT) Inhibiti on of Cord Blood Derived B and T Cells Expansion. Adv Pharm Bull 7: 215-220.

42. Dunlap J, Cascio MJ, Stacey X, Click S, Troxell ML (2017) TdT-positive Infiltrate in Inflamed Pediatric Kidney: A Potential Diagnostic Pitfall. The Am J Surgical Pathol 41: 706-716.

43. Akbari MF, Lange-Turenhout EA, Aries IM, Pieters R, den Boer ML (2013) MiR-125b, miR-100 and miR-99a co-regulate vincristine resistance in childhood acute lymphoblastic leukemia. Leuk Res 37: 1315-21.

\section{Acknowledgement}

This study was supported by Universidad Autónoma de Guerrero. Luis Antonio Martinez Jiménez (CVU/Becario: 857868/627649) was recipients of mastery fellowships from CONACYT. 